\title{
EN EL ESPEJO DEL YO INTERIOR: FANNY CALDERÓN DE LA BARCA Y SUS OTRAS MEXICANAS
}

\author{
IN THE MIRROR OF THE INNER SELF: \\ FANNY CALDERÓN DE LA BARCA AND HER OTHER MEXICANS
}

\author{
Estela Roselló Soberón \\ (iD) orcid.org/0000-0003-2159-6758 \\ UNAM-Instituto de Investigaciones Históricas \\ México \\ estela.rosello@gmail.com
}

\begin{abstract}
This article has the purpose of exploring the complex nature of the process of construction of the inner self of a European woman like Fanny Calderón de la Barca. It points out the importance of the confrontation with American otherness in the process of construction of this said individual feminine identity. The purpose of these pages is to show and analyze the tensions and contradictions of this hybrid identity, as well as the ambivalence of the sensitive universe that caused Fanny to oscillate between rejection and empathy towards her "others", in the process of self-construction and self-knowledge.
\end{abstract}

Keywords: cultural hibrydism, femenine identities, inner self, otherness, sensibilities.

\section{Resumen}

Este artículo tiene el propósito de explorar la naturaleza compleja del proceso de construcción del yo interior de una mujer europea como fue Fanny Calderón de la Barca y la importancia que tuvo la confrontación con la otredad americana en el proceso de construcción de dicha identidad femenina individual. El objeto del mismo es mostrar y analizar las tensiones y contradicciones que formaban parte de esta identidad híbrida, así como la ambivalencia del universo sensible que hizo que Fanny oscilara entre el rechazo y la empatía hacia sus "otras", en ese proceso de autoconstrucción y autoconocimiento.

Palabras clave: hibridismo cultural, identidad femenina, otredad, universo sensible, yo interior. 


\section{Introducción: otredad y pertenencia en el contexto imperial}

Los imperialismos del siglo XIX dieron origen a muchas relaciones e identidades que se construyeron a partir de la proyección de múltiples reflejos del mundo europeo en otros territorios. También, gracias a la construcción de nuevos reconocimientos culturales que si bien habían tenido algunos antecedentes en la primera globalización de los siglos XVI y XVII, para el siglo XIX habían adquirido tintes de nuevas sensibilidades liberales, ilustradas y revolucionarias, propias de los tiempos modernos. La expansión comercial, la colonización política y la exploración geográfica de las naciones occidentales en diversas latitudes se tradujeron en la intensificación de los contactos entre pueblos muy distintos entre sí que, al encontrarse por primera vez, percibieron sentimientos y sensaciones a veces vinculados con la vivencia de la pertenencia y otras veces relacionados con la experiencia de la otredad.

Mientras los imperios europeos se disputaban la hegemonía económica, política y cultural del mundo, en el ámbito de la vida privada el fenómeno de la expansión imperial encontró expresión en la conformación interna de hombres y mujeres que, al enfrentarse con la diferencia y la diversidad humana, se vieron obligados a preguntarse por sus propias identidades personales europeas, ideológicas y nacionales. En este proceso histórico y cultural de construcción del yo europeo del siglo XIX, el sujeto osciló entre el reconocimiento de la diferencia y la búsqueda de la igualdad; entre la comprobación de señales y signos físicos, culturales, sociales y económicos que hablaran de aquello que era particular y distinto a lo propio y la constatación de las expresiones y manifestaciones comunes entre todos los seres humanos.

A decir verdad, si algo caracterizó a aquel proceso de construcción del yo occidental en la época contemporánea, fue la naturaleza híbrida y permeable de las identidades individuales que resultaron de él. Para muchos europeos que viajaron de un lugar a otro y que establecieron su morada en continentes distintos a los de su lugar de origen, la experiencia del desplazamiento los dotó de una nueva conciencia que les permitió reconocerse a sí mismos en un caleidoscopio en donde el juego de espejos proyectaba imágenes múltiples de un mismo individuo.

\section{Identidades femeninas en el siglo XIX: un yo en transformación}

En aquel universo de búsqueda y construcción de identidades del siglo XIX, las mujeres europeas que voluntariamente, o de manera forzada, se vieron obligadas a viajar a otros continentes vivieron procesos internos de cambios profundos en sus personalidades. Estos procesos de transformación del sujeto femenino se dieron dentro de límites culturales, sociales e históricos específicos. En realidad, el drama de la construcción de identidades múltiples, cambiantes y mixtas de muchas mujeres viajeras europeas se vivió en medio de las contradicciones propias de aquella época. Frente al surgimiento de nuevas burguesías democráticas y liberales que veían en la equidad el valor para construir progreso y civilización, los vestigios morales del Antiguo Régimen generaron nuevas jerarquías imperiales regidas por fuertes sentimientos de superioridad y racismo. También los ámbitos de lo público y lo privado se vieron afectados por las nuevas nociones acerca del poder, de la autoridad y de la participación ciudadana en la organización de la sociedad. Esto último afectó, directamente, la definición de los roles y los estereotipos de aquello que se consideraba propio o no de las mujeres.

El propósito de este artículo es rastrear el contexto en el que se forjaron algunos rasgos del proceso de construcción del yo interior de una mujer que, como muchas otras

1 El problema de la construcción del yo femenino ha estado presente como tema de interés primordial en mis investigaciones más recientes. Una verdadera reflexión sobre de qué se trataba ser mujer en cada época no puede olvidar las preguntas sobre eso que Denis Crouzet ha señalado como "el movimiento introspectivo que mueve a las mujeres a preguntarse sobre sí mismas" (Crouzet y Zemon Davis, 2006: 115). 
de sus contemporáneas, vivió la experiencia del viaje y, por ende, la experiencia de la confrontación con lo otro como una situación que más bien la llevó a preguntarse por su propia identidad y a encontrarse, de manera consciente o inconsciente, con la heterogeneidad de su yo. Y es que como se verá a continuación, para Fanny Calderón de la Barca, su estancia de dos años en México fue una experiencia que adquirió significados particulares, propios de su realidad vivida. A decir verdad, para Madame Calderón de la Barca, el viaje a tierras mexicanas significó una experiencia compleja y contradictoria que le dio pistas para comprender qué la hacía distinta y qué la hacía similar a los seres humanos con los que se topó en una tierra que por momentos le pareció bárbara e insoportable, y por otros, pintoresca y entrañable. En esa toma de conciencia sobre la otredad y sobre ella misma, las fronteras entre una cosa y otra no siempre fueron rígidas ni estáticas, sino más bien porosas y cambiantes.

En las siguientes reflexiones se busca rastrear y reconstruir aquel proceso de encuentro y confrontación individual; para hacerlo, se ha elegido la clave de emoción, es decir, se buscará esclarecer los significados culturales ocultos detrás del universo emocional que rodeó a dicho proceso íntimo. Más específicamente: lo que se pretende es analizar la naturaleza del proceso de construcción del yo interior de la Marquesa Calderón de la Barca a partir del contexto cultural que dio sentido al encuentro con mujeres mexicanas a quienes convirtió en las depositarias de su otredad. ${ }^{2}$ Como podrá observarse a lo largo de este artículo, los efectos emocionales de aquel encuentro con las otras fueron siempre ambivalentes, paradójicos y contradictorios y oscilaron, en su mayoría, entre los sentimientos de desprecio-superioridad y los de simpatía-admiración.

\footnotetext{
2 Aquí vale la pena recordar aquello que dice Beatriz Ferrús Antón sobre las mujeres viajeras del siglo XIX, sujetos que, de acuerdo con la historiadora española, "desafiaron su destino simbólico... [cruzaron] fronteras para encontrarse con un colectivo de mujeres cuyo valor trasnacional poseería un notable poder desestabilizador" (Ferrús Antón, 2011: 14).
}

\section{Una viajera e inmigrante de su tiempo: Fanny Calderón de la Barca}

En su número 76 de junio-septiembre de 1845, la revista Quarterly Review de Londres publicó un artículo titulado "Lady Travellers". En él, se presentaba una fuerte crítica a varias viajeras británicas que, de acuerdo con la mirada victoriana del autor, no cumplían con lo que se esperaba de una verdadera dama inglesa, es decir, comportarse como una mujer "educada, comedida, llena de decoro, escrupulosa y [de] sano juicio" (Gerassi, 2009: 741). En realidad, la crítica del autor de la publicación periódica reflejaba la preocupación compartida por muchos europeos del siglo XIX que vieron con desconcierto que las mujeres de su tiempo ya no se quedaban en casa, a la espera de sus hombres que, durante siglos, habían viajado en busca de nuevas experiencias y nuevos mundos, para hacer gala de su masculinidad (Gilroy et al., 2000: 7). En lugar de esto, al llegar el siglo XIX, y, a diferencia de lo que había ocurrido tradicionalmente, muchas mujeres europeas decimonónicas se vieron obligadas a emigrar, emprendieron viajes largos a lugares lejanos y más aún, escribieron cartas, relatos, diarios y narraciones para describir sus experiencias en tierras extrañas. A decir verdad, en sus escritos, muchas de estas viajeras mostraron que sus experiencias de viaje habrían de estar definidas por miradas y sensibilidades femeninas que, en cierto sentido, tal como han señalado autores dedicados al estudio de dichos sujetos históricos, fueron distintas a las de los viajeros masculinos de la época (Gilroy et al., 2000: 7). ${ }^{3}$

3 De acuerdo con Amanda Gilroy, esta mirada femenina habría estado entrenada para mirar cosas que los hombres no habrían observado de la misma manera, o a las que no habrían dado igual importancia o significado: los espacios domésticos, las costumbres, las relaciones interpersonales, por ejemplo. Es también Mary Louise Pratt quien habla de un imperialismo femenino que se habría traducido en esa mirada particular hacia el otro, más propia de las mujeres que de los hombres europeos. Para Pratt (1992), la melancolía presente en los escritos de viajes femeninos habría sido uno de dichos rasgos propios de la experiencia de las mujeres románticas europeas que conocieron otras geografías. 
Entre las viajeras que el autor del artículo "Lady Travellers" criticaba, se encontraba, en palabras de otra publicación de la época -The Edimburgh Review-, "una escocesa criada en Nueva Inglaterra, casada con un español con quien vivió dos años como embajadora en México; una curiosa combinación de accidentes personales" (Gerassi, 2009: 743). Aquella mujer singular no era otra que Frances Erskine Inglis, esa escocesa peculiar, mejor conocida por amigos y parientes como "Fanny" y que, con el paso del tiempo, habría de convertirse en Madame Calderón de la Barca.

En efecto, la vida de Fanny no fue, precisamente, la de una escocesa estándar, establecida en la afable campiña de Edimburgo. La vida de esta mujer fue, más bien, la de una viajera europea e inmigrante de principios del siglo XIX, cuya existencia y personalidad se construyeron, ciertamente y tal como lo señalaba el autor de la Edimburgh Review, a partir de una serie de accidentes del destino, pero, además, a partir del contexto cultural e histórico específico en que vivió. Por otro lado, sería absurdo obviar el conjunto de decisiones e iniciativas personales que sin duda también incidió en el devenir de esta joven escocesa de su tiempo. A decir verdad, la de Fanny es una historia de vida que muestra, tal como lo ha sugerido Natalie Zemon Davis en muchos de sus trabajos, las tensiones típicas que hay entre la vida íntima de los sujetos y las realidades políticas, culturales y sociales en las que transcurre su existencia.

\section{De Europa a América}

Frances Erskine Inglis nació en Edimburgo en 1804. Su padre fue William Inglis de Maners, un rico abogado whig, terrateniente cercano a la corte y a la nobleza escocesa; su madre, Juana Stein, perteneció a una familia burguesa productora de whiskey (Fisher, 2018: s.p.). Frances era la quinta de ocho hermanos. La primera parte de la vida de esta familia de clase media alta escocesa transcurrió tranquila en su ciudad natal; sin embargo, cuando Fanny cumplió 24 años de edad, su padre enfrentó muchos problemas económicos que lo llevaron a la bancarrota, por lo que la familia Inglis tuvo que emigrar de Edimburgo a Boulonge. Allí, en aquella ciudad francesa, los Inglis Erskine residieron durante tres años, antes de la muerte del padre (Teixidor, 2000: XVI). Frente al terrible acontecimiento, la madre de Fanny, como la llamarían toda la vida sus hermanos, madre y amigos más cercanos, decidió emigrar con sus hijas a la ciudad norteamericana de Boston, lugar donde se establecieron y abrieron una escuela para niñas (Ramírez Rodríguez, 2010: 3).

Para 1830, Boston era una ciudad llena de vida. Su tradición republicana se reflejaba en la existencia de la universidad, los cafés, las bibliotecas, escuelas y circulación de diversos periódicos (Teixidor, 2000: XVI). Pero no sólo eso: la sociedad bostoniana contaba con una fuerte participación política y social femenina. Ya desde el siglo XVIII, muchas mujeres de la ciudad habían buscado expresarse ejerciendo el oficio de la escritura, a través del género de la poesía política. ${ }^{4}$ De esta manera, mujeres como Hannah Mather Crocker, Sarah Kemble Knight, Jane ColemanTurell o Sarah Parsons Moorhead colocaron en sus escritos muchos temas pertenecientes al ámbito privado en la esfera pública (Hunt, 2014: 149). Por otro lado, además de escribir, muchas mujeres de la ciudad norteamericana eran miembros de la logia masónica de Saint Anne, lo mismo que participaban en muchos actos de benevolencia y colaboraban en instituciones educativas, como la School of Industry para niñas pobres de la ciudad (Hunt, 2014: 150).

Las mujeres bostonianas interesadas en integrarse a la vida pública vieron en la educación un mecanismo liberador para su género, así como el medio para construir una sociedad igualitaria, que incluyera a las mujeres entre la ciudadanía (Hunt, 2014: 149). Fue en esa sociedad republicana e ilustrada donde la señora Inglis y sus hijas abrieron

4 De acuerdo con Eileen Hunt Botting, a partir del siglo XVIII muchas mujeres bostonianas escribieron poesía y literatura y convirtieron este género en una expresión muy importante de intervención feminista en la esfera pública norteamericana (Hunt, 2014: 149). 
su escuela para niñas en la Chestnut Street. En ella, Fanny, su madre y sus hermanas ofrecieron cursos de francés, italiano, piano, arpa, literatura, filosofía moral e historia (Fisher, 2018: s.p.). Pronto, la señora y las señoritas Inglis se dieron a conocer entre los círculos letrados de la ciudad y allí Fanny se hizo muy amiga de algunos jóvenes cultos y liberales como George Ticknor y W.H. Prescott. Fue precisamente en casa de este último que, en 1838, Frances conoció a Ángel Calderón de la Barca, ministro plenipotenciario de España en Estados Unidos. Poco tiempo después, Fanny y don Ángel se casaron en Nueva York, listos para emprender el viaje a La Habana, Cuba. Poco tiempo después, en diciembre de 1839 el gobierno mexicano reconoció a don Ángel Calderón de la Barca como su primer ministro plenipotenciario español (Ramírez Rodríguez, 2010: 3). ${ }^{5}$ Efectivamente, el matrimonio Calderón de la Barca se estableció en México entre diciembre de 1839 y enero de 1841. Durante aquella estancia de dos años, Fanny escribió a su madre y a sus hermanas varias cartas en las que compartió con ellas las experiencias, sensaciones, sentimientos y reflexiones cotidianas que generó en ella su paso por aquel nuevo país hispanoamericano.

\section{Vida en México y la tradición de los diarios de viaje entre las mujeres escocesas del siglo XIX}

Dos años después de que Fanny abandonara México, su muy querido amigo W.H. Prescott la animó para que eligiera 54 cartas de la correspondencia que había establecido con su madre y sus hermanas. Esto, con el propósito de publicarlas en Boston y en Londres en un libro que llevaría el título de Vida en México (Ramírez Rodríguez, 2010: 3). ${ }^{6}$

Es probable que el gusto de Fanny por escribir, así como el género que eligió para hacerlo, provinieran de una fuerte tradición

\footnotetext{
5 Cuando Fanny y Ángel se casaron, él tenía 48 años y ella 33.

6 La primera edición del libro se publicó en Boston en 1843; la segunda fue la de Londres. En ambos casos se omitió el nombre completo de Fanny, quien sólo aparecía como M.C. de la B. por respeto diplomático.
}

cultural. En Escocia, la escritura femenina había tenido un lugar importante desde los siglos XVII y XVIII. En aquellas centurias, autoras como Catherine Trotter (1679-1749) o Jean Marishall (1765-1789), por ejemplo, habían sido famosas gracias al gran éxito de sus obras de teatro (Simonton y Barclay, 2016: 3). ${ }^{7}$ Esto, en el contexto de una sociedad ilustrada en donde las mujeres deseaban participar activamente en la vida pública, no obstante el estereotipo cultural que relegaba la expresión del sexo femenino al ámbito de la vida privada. ${ }^{8}$

Ciertamente, la prensa periódica escocesa de los siglos XVIII y XIX había sido un espacio reservado a las plumas masculinas; por ello, muchas mujeres escritoras interesadas en manifestar sus ideas y opiniones sobre asuntos públicos optaron por escribir diarios y cartas que, si bien parecerían producciones reservadas al universo íntimo y privado de los sujetos, en realidad, en los siglos XVIII y XIX permitieron que las mujeres plasmaran reflexiones sobre situaciones y problemas sociales, políticos y culturales de su época. Estos escritos contaban con un público particular: ya fueran los corresponsales a quienes iban dirigidas las cartas o los grupos de personas entre quienes se leía en voz alta este tipo de documentos en un afán de informar o divertir. ${ }^{9}$ En todo caso, al llegar el siglo XIX los diarios de viajeros se

7 De acuerdo con Deborah Simonton (2016), las mujeres escocesas fueron sujetos muy activos en la vida intelectual de la sociedad ilustrada del siglo XVIII.

8 Glenda Norquay explica cómo las mujeres escocesas que practicaron la escritura hicieron de dicha actividad el medio para encontrar un lugar dentro de las formas dominantes de la escritura masculina, que eran la prensa periódica y el drama (Norquay, 2012: 2). Por su parte, Deborah Simonton explica las dificultades que hay en pensar lo público y lo privado como categorías rígidas o realidades absolutamente separadas (Simonton y Barclay, 2016: s.p.).

9 Pensar que la correspondencia y los diarios fueron géneros sobre todo femeninos es un lugar común aceptado por muchos historiadores. Sin embargo, Betty Hagglund explica que, en realidad, muchos hombres europeos también escribieron cartas y diarios ya desde el siglo XVII. Es también esta historiadora quien señala que entre los siglos XVI y XIX, ni las cartas ni los diarios se consideraban escritos privados, puesto que la gente los leía en lugares públicos o en familia durante el invierno como forma de entretenimiento (Hagglund, 2010: 5). 
convirtieron en uno de los géneros más populares entre los lectores de las sociedades norteamericana y europea ilustradas, burguesas y liberales. En el caso particular de Escocia, hubo varias mujeres escritoras que se dedicaron a narrar la experiencia de sus viajes dentro y fuera de su propia nación. ${ }^{10}$ Fanny Calderón de la Barca formó parte de esta historia de viajeras escritoras que, al narrar su experiencia a públicos o corresponsales particulares -en su caso personal a su madre y a sus hermanas-, vivieron un proceso de autoconstrucción y definición de su yo (Ramírez Rodríguez, 2010: 8)."1

\section{Una sensibilidad femenina educada}

Como muchas otras jóvenes de las clases medias altas escocesas del siglo XIX, Francis se educó en el pensamiento ilustrado y liberal de la época que, en su versión escocesa, incluía el valor femenino de la politeness (Simonton y Barclay, 2016: s.p.).12 Más allá de leer el periódico, participar en tertulias literarias, asistir a las bibliotecas públicas o formar parte de sociedades filantrópicas, las mujeres escocesas de los sectores urbanos debían saber coser, leer, cocinar y tocar instrumentos musicales. Las particularidades de este tipo de educación femenina entre las clases medias de la Escocia del siglo XIX incidieron en la conformación de una mirada imperialista singular que influyó en la mirada con la que Fanny Calderón de la

10 El libro de Betty Hagglund antes mencionado da cuenta, precisamente, de varias mujeres escocesas que realizaron viajes dentro de la propia Escocia y escribieron diarios para plasmar su experiencia. Por su parte, Deborah Simonton recuerda, entre otras, a Maria Ridell, quien a principios del siglo XIX publicara su diario sobre los viajes que realizó a el Caribe y a Madeira (Simonton y Barclay, 2016: s.p.).

11 En su artículo sobre Fanny Calderón de la Barca, Rodolfo Ramírez Rodríguez plantea la importancia del viaje en la recreación del yo de la marquesa. Es él, también, quien recuerda la popularidad que tuvieron los diarios de viajeros en Estados Unidos y en Europa en el período entre 1830-1840, que coincide, precisamente, con la estancia de Fanny y don Ángel Calderón de la Barca en México.

12 De acuerdo con Deborah Simonton (2016), este concepto tuvo mucha relación con el interés de las clases medias escocesas en proyectarse como sectores civilizados, cosmopolitas y democráticos en medio de las políticas expansionistas del Imperio británico.
Barca se aproximó a las mujeres mexicanas. Evidentemente, aquella mirada estaría condicionada por todo aquello que la constituía a ella misma como una mujer de un tiempo particular y de múltiples geografías culturales, espaciales y emocionales distintas. ${ }^{13}$

Durante los años previos de su llegada a México, Fanny se movió en un círculo muy interesado en el mundo, las costumbres y la historia hispánicos (Ramírez Rodríguez, 2010: 6). ${ }^{14}$ Se sabe que antes de comenzar el epistolario para su familia, Francis ya había leído las Cartas de relación de Hernán Cortés, el Ensayo político del barón von Humboldt, las obras de Clavijero, de Zavala y de Mora. Pero, además, la viajera escocesa, esposa del ministro Calderón de la Barca, también había leído a autores románticos como lord Byron o Schiller.

Sin duda alguna, el universo emocional de Fanny Calderón de la Barca abrevaba, en mucho, del pensamiento y la literatura romántica de su época. Lo mismo que sus casi contemporáneas, Jane Austen, Anne Radcliffe o Mary Shelley, Fanny Calderón de la Barca estuvo interesada en plasmar las costumbres, los sentimientos y la vida doméstica y familiar del país al que viajó y que quería describir a su madre y a sus hermanas en su correspondencia. Al ejercer su capacidad creativa y su posibilidad para imaginar y recrear los mitos, las leyendas y los paisajes y personajes de la tierra mexicana que la recibía, Fanny demostraba que las mujeres como ella eran tan competentes racional e intelectualmente como los hombres que se dedicaban a escribir, a pensar y a reflexionar en su época (Mellor, 1993: 9). ${ }^{15}$

13 En el capítulo dedicado a Fanny Calderón de la Barca, Beatriz Ferrús Antón (2011) menciona el interés que Francis tuvo en abordar la realidad femenina mexicana "desde su propia condición de mujer". Una mujer que, ciertamente, se construyó a sí misma desde múltiples facetas.

14 Es importante recordar que en 1837, William Prescott había publicado su famosa Historia de los reyes católicos y que en 1843 habría de publicar su Historia de la Conquista de México, escrita a partir de documentos, por cierto, que la propia Francis proporcionó a su ilustre amigo para tal efecto.

15 Mellor estudia las diferencias entre los temas que les interesaba explorar a las mujeres y a los hombres románticos. Para la profesora de literatura británica, las autoras románticas basaron su atención en temas vin- 
Por otro lado, al concentrarse en describir asuntos microscópicos y aspectos cotidianos poco trascendentes para la mirada masculina, Fanny plasmó en sus escritos una mirada y una sensibilidad femenina particular, que privilegiaba la experiencia de redefinir lo propio desde aquello que le generaba simpatía o rechazo (Mellor, 1993: 11). ${ }^{16}$

En efecto, la sensibilidad de Frances había sido educada, desde su infancia escocesa, en los valores del liberalismo ilustrado con los que volvió a encontrarse al llegar a Boston. Estos valores le permitieron, sin duda, interpretar su existencia en todas las latitudes en las que se estableció a lo largo de su vida. También, como se ha dicho ya, el universo emocional mediante el cual Fanny se vinculó con los otros, con sus iguales y con ella misma fue, en gran medida, un universo romántico. Sin embargo, hay un elemento más que es imposible soslayar cuando se intenta reconstruir la manera en que Frances se educó sentimentalmente y forjó una sensibilidad femenina particular. Si bien Fanny había recibido la educación de una señorita escocesa liberal y se había nutrido del romanticismo propio de su época, también es cierto que la familia Inglis había tenido vínculos importantes con la nobleza terrateniente y con la aristocracia feudal de su tierra natal. En este sentido, es posible suponer que la conexión cotidiana con don Ángel Calderón de la Barca, su marido, hombre bien educado, culto, formado en los valores más tradicionales del catolicismo

culados con la familia y la comunidad. Pero, además, dichas mujeres tuvieron especial interés en insistir en la igualdad entre los hombres y las mujeres. Entre los valores reivindicados con mayor fuerza por las mujeres románticas del siglo XIX se encontraron la amistad, la empatía y la simpatía. Por otro lado, de acuerdo con esta autora, dichas mujeres estuvieron muy preocupadas por definir nuevamente el significado de "lo propio y de la propiedad en su vida" (Mellor, 1993: 4-5). En el caso de Fanny Calderón de la Barca, como se verá más adelante, la manera de aproximarse a las mujeres mexicanas durante su estancia en el país hispanoamericano osciló, siempre, entre la experiencia del rechazo y la de la empatía.

16 De acuerdo con Anne K. Mellor, uno de los rasgos más característicos de la sensibilidad femenina romántica fue la importancia que en ella tuvieron, por un lado, el interés en definir lo propio, y por otro, los sentimientos relacionados con la amistad y la simpatía. hispánico, haya sido fácil, por lo menos, en lo que se relacionaba con asuntos que generaran nostalgia o melancolía por las tradiciones, la hegemonía y el antiguo orden del imperio español. Es importante recordar, además, que estos sentimientos eran muy propios de la sensibilidad romántica del siglo XIX (Standish, 2010: s.p.). ${ }^{17}$ No hace falta subrayar que esta multifacética educación sentimental generó un cúmulo de tensiones y contradicciones internas que emergieron, a cada instante, en la experiencia del viaje de Fanny a México, pero, sobre todo, en cada momento en que Frances se topó con las otras: esas señoritas, señoras y damas mexicanas que durante dos años la confrontaron con su propio yo.

\section{Fanny y la experiencia del viaje}

Para fines del siglo XVIII y la primera mitad del siglo XIX, la literatura de viajeros adquirió un interés muy particular entre el público de las sociedades imperiales europeas. Las cartas y los diarios de hombres y mujeres que se enfrentaban con nuevos paisajes, costumbres exóticas, mitos y leyendas desconocidos generaron curiosidad e interés entre audiencias que comenzaban a compartir sentimientos de orgullo y superioridad, ambos indispensables en la construcción de las futuras identidades colonialistas y nacionalistas europeas de aquel momento.

Para los viajeros del siglo XIX, y, en el caso muy específico de Fanny Calderón de la Barca, la escritura de un diario o de correspondencia personal implicó la posibilidad de expresar el proceso de auto transformación propia de un viaje; el encuentro con uno mismo a partir de la confrontación con lo no propio y con la otredad.

Para Fanny, este proceso de auto reconocimiento y de diferenciación de los demás se dio a partir del diálogo imaginario con

17 Vale la pena recordar que, después de su matrimonio con el embajador español, Fanny, de origen presbiteriano, terminó por convertirse al catolicismo, para gran alegría de su piadoso marido. Sobre la importancia que tuvo la melancolía en la sentimentalidad romántica, ver Susan Wolfson, quien señala que este sentimiento se identificó, sobre todo, con la sensibilidad femenina del siglo XIX (2015: 445). 
unos destinatarios particulares: su madre y sus hermanas, sujetos a quienes Frances seguramente reconocía como iguales y con quienes podía compartir las emociones de distanciamiento que experimentaba frente a sujetos que, efectivamente, veía con extrañeza. Si bien el aquí geográfico de las cartas de Fanny era México, dicho país significaba el allá imaginario que la colocaba junto con su madre y sus hermanas en el lugar que le permitía hablar de nosotros frente a los otros (Hagglund, 2010: 2). ${ }^{18}$

De manera que, como se verá a continuación, para Fanny Calderón de la Barca, la estancia de dos años en México ofreció un espejo para reflejar imágenes diversas de su experiencia vivida, es decir, de todo aquello que la constituía como una mujer europea de su tiempo, llena de tensiones y contradicciones que la acercaron o la alejaron de esas otras mexicanas a quienes a veces se aproximó desde el rechazo y el desprecio, y otras, desde la amistad y la empatía.

\section{Fanny y el espejo mexicano}

Tal como señala Betty Hagglund, ningún viajero registra sólo lo que ve. En todas las épocas, las personas viajan con sus propias percepciones y observan la realidad de acuerdo con sus propios prejuicios, ideas, creencias y valores (Hagglund, 2010: 1). ${ }^{19}$ En el caso de Fanny Calderón de la Barca, esta viajera europea se introdujo en los espacios más íntimos de la sociedad mexicana con todo el bagaje de su historia personal. Y así, a lo largo de su estancia en México, la marquesa se encontró con muchas señoras y señoritas a las que describió a partir de todo aquello que formaba parte de sus propios códigos culturales y personales.

\footnotetext{
18 Este fenómeno interior recuerda aquello que explica Dorothy McMillan sobre la literatura de viaje. De acuerdo con ella, en toda literatura de viaje, las ideas del aquí y del ahora tienen una estrecha relación con el público al que se dirigen. La geografía en la que se localizan los escuchas de dichas obras influye en la manera en que su autor las escribe.

19 De acuerdo con Hagglund (2010), nadie escribe solamente como un individuo. En la escritura de todo ser humano, las descripciones y los juicios de valor revelan muchos elementos de clase, de género y de nacionalidad.
}

Son muchos los pasajes de Vida en México en que Fanny describe a sus otras mexicanas. La manera de referirse a ellas muestra un universo de emociones complejas y contradictorias generadas a partir de lo que observaba sobre su físico, su arreglo personal, su relación con la servidumbre o con los hombres que las rodeaban $\mathrm{y}$, por supuesto, sobre su educación. El racismo, los sentimientos de superioridad, la sorpresa y a veces, incluso, el desprecio, se alternan con emociones como la simpatía, el agrado, la admiración o la compasión. La ambivalencia con que Fanny miró a las mujeres mexicanas será una constante a lo largo de todo su libro.

Así, por ejemplo, en su carta del 25 de febrero de 1840, Madame Calderón contaba a sus corresponsales lo siguiente:

Al llegar por primera vez de los Estados Unidos, en donde una mujer fea es cosa rara, no deja uno de sorprenderse, a primera vista, de una ausencia, en general, de belleza en México [...] el brillante cutis y la esbelta figura de una inglesa sorprenden a todo el mundo. La belleza de expresión y las facciones finamente cinceladas de las españolas, nos sobrecogen como la suave luz de la luna; mientras que una mujer francesa, por sencilla que sea, posee una manera tan graciosa de decir cosas agradables [...] la belleza de las mujeres de aquí consiste en los soberbios ojos negros, en el hermoso cabello oscuro, en la hermosura de brazos y en su pequeño pie. Y sus defectos, de que con demasiada frecuencia son cortas de estatura y demasiado gordas, de que sus dientes suelen ser malos y el color de su tez no es el olivo pálido de las españolas ni el moreno brillante de las italianas, sino un amarillo bilioso [...] sin embargo, cuando una mexicana posee dientes blancos y buen color, cuando no se ha puesto muy gorda [...] debe ser por demás hermosa (Calderón de la Barca, 2000: 86).

Como es fácil advertir, el primer encuentro de Fanny con sus otras generó en ella una mezcla de emociones contradictorias. Al advertir el color, la complexión, los rasgos de las manos femeninas del país extranjero, 
la marquesa hacía eco de todos sus prejuicios racistas y eurocentristas. En principio, las mexicanas le parecían feas, gordas, chaparras, con malos dientes, amarillas. Lo que ella observaba en los cuerpos de las mexicanas no tenía nada que ver con los estereotipos de belleza y elegancia aceptados por las élites blancas occidentales europeas de las que ella formaba parte. Sin embargo, más adelante, como si tuviera que hacer un revés en su propio fuero interno, Fanny señala que a veces, las mexicanas podían llegar a ser muy hermosas.

En otros momentos de su encuentro con las otras, Fanny interpretaba la realidad mediante una sensibilidad romántica que le permitía mirar las cosas desde una lente que reflejaba colores alegres y pintorescos. Esta mirada se activaba, sobre todo, a la hora de describir a las mujeres indias con las que se topaba en su vida diaria:

En cuanto a las indias, las que vemos todos los días traer al mercado sus frutas y sus legumbres, son, hablando en términos generales, sencillas, de dulce apariencia [...] algunas veces se queda uno sorprendido de encontrar entre el vulgo caras y cuerpos tan bellos, que bien puede suponerse que así sería la india que cautivó a Cortés [...] (Calderón de la Barca, 2000: 86).

Como buena romántica, Fanny no dejaba de ver con nostalgia aquel pasado glorioso de dominio español en México. Un pasado dorado que había dotado a la nación de costumbres y tradiciones valiosas, vestigios de la historia que aún se podían percibir en la vida diaria. Los mitos de ese pasado hispánico la conmovían. La figura del héroe hispánico, Cortés, la cautivaba y el recuerdo de la Malinche la emocionó en diversos instantes.

Ahora bien, muchas de las emociones propias de su sensibilidad romántica se mezclaban con otras que procedían de su conciencia liberal, republicana y democrática. Así, en varios pasajes en los que describe su encuentro con las señoras, las damas y las señoritas mexicanas, Fanny se coloca como una defensora de la igualdad entre los seres humanos. Sin duda, entre las cosas que Madame Calderón de la Barca detestó más de la sociedad mexicana, fueron la desigualdad y los contrastes sociales que existían entre los sectores pobres y los estratos ricos de aquel país. Habla Madame Calderón al respecto:

En contraste con el lujo excesivo de las señoras, se ve atravesar a las indias con su trote la plaza, las trenzas de su cabello negro entretejidas con un listón rojo y sucio y a la espalda un niño, se diría que, de caoba, cara al cielo, cabeceando con los vaivenes del paso, y es un milagro no se les disloque la nuca (Calderón de la Barca, 2000: 119).

Para Fanny, el problema de la desigualdad en la sociedad mexicana estaba estrechamente vinculado con el pésimo nivel de educación y la poca exposición a la cultura que encontraba entre las mujeres de dicha nación. Ella, que era maestra y que había sido educada en los valores liberales femeninos de la politeness escocesa y la ilustración republicana bostoniana, miraba con irritación la ignorancia femenina de un país que, a final de cuentas, no dejaba de parecerle bárbaro e incivilizado. Nuevamente escribe Fanny:

Hablando en términos generales, he de deciros que las señoras y señoritas mexicanas escriben, leen y tocan un poco, cosen y cuidan de sus casas y de sus hijos. Cuando digo que leen, quiero decir que saben leer, cuando digo que escriben no digo que lo hagan siempre con buena ortografía, y cuando digo que tocan, no afirmo que posean, en su mayoría, conocimientos musicales. Si comparamos su educación con la de las muchachas de Inglaterra o de los Estados Unidos, no es una comparación, sino un contraste (Calderón de la Barca, 2000: 194).

Sin duda, el atraso en que vivían las mujeres mexicanas molestaba a la esposa del embajador español. Sin embargo, convencida de las bondades del progreso europeo, 
por momentos, Fanny condescendía un poco y abría una pequeña posibilidad de esperanza:

Sucede con frecuencia que las muchachas peor educadas sean hijas de hombres muy inteligentes, pero pegadas a las costumbres de sus abuelos [...] asisten asiduamente a la Iglesia y llegan a bordar y cantar un poco [...] Donde se encuentra un criterio más amplio es, sobre todo, entre las familias que han viajado por Europa y han visto la educación tan diferente que recibe la mujer en los países extranjeros (Calderón de la Barca, 2000: 196).

Así, las tensiones y contradicciones internas generadas ante el encuentro con aquellas otras frívolas, incultas y atrasadas, a veces se expresaba en esa oscilación que iba del desprecio a la condescendencia, del fastidio a la simpatía, de la repulsión a la admiración. Otra vez Fanny: "Aunque raras veces graciosas, [las señoras mexicanas] nunca se aturden [...] tienen mucho talento natural y cuando han sido educadas con esmero no hay mujeres que puedan superarlas. De lo que se llama sociedad literaria no hay nada, por supuesto" (Calderón de la Barca, 2000: 195).

Ahora bien, a la conciencia híbrida imperialista, eurocentrista, y al mismo tiempo liberal de Fanny habría que sumar su herencia aristócrata y feudal, lo mismo que muchas ideas y creencias propias de la Inglaterra victoriana. En este sentido, llaman la atención sus opiniones sobre la naturaleza de las criadas o sirvientas mexicanas, lo mismo que las relaciones entre los hombres y las mujeres de aquel país. Por ejemplo, se queja Madame Calderón en su carta del 3 de junio de lo siguiente: "Me pedís que os diga cómo encuentro a las criadas mexicanas. Hasta ahora he eludido tema tan ingrato que me tiene tan fastidiada. Los defectos de los sirvientes son una fuente inagotable de quejas [...]" (Calderón de la Barca, 2000: 161).

Con frecuencia, la escocesa narra a su madre y a sus hermanas el horror que le producen la suciedad, la pereza y la indolencia de las malas criadas mexicanas. En los pasajes que dedica al tema, encuentra sumamente desagradable la costumbre que dichas mujeres tienen de llevar el pelo suelto "enmarañado, sin peinar y enredándose siempre en todas partes". La admiración por la higiene y el orden, dos valores de las sociedades "modernas, civilizadas e ilustradas" europeas, ausentes en la mexicana, al menos en la imagen de la servidumbre, se imponían en aquellos instantes que debieron haber sido para ella momentos de muy desagradables desencuentros.

Por otro lado, también en relación con las criadas mexicanas, como ella las Ilamaba, había otras situaciones que disgustaban mucho a Fanny. ${ }^{20}$ Entre ellas, su ineficacia, informalidad e impuntualidad. La esposa de don Ángel Calderón de la Barca reflexionaba al respecto y se dirigía a sus corresponsales, mujeres pares, quienes, de acuerdo con ella, seguramente la comprenderían, y a las que comentaba lo fácil que sería deshacerse del fastidio de contratar a una buena sirvienta mexicana sin equivocarse, si los patrones dieran cartas de recomendación verdaderamente confiables. De hecho, para Fanny una de las costumbres más exasperantes de los mexicanos era la de recomendar a cualquiera, incluso a aquellos que no contaban con verdaderas virtudes. Así, el valor de la meritocracia, inclusive para medir el talento y la naturaleza de la servidumbre apta o no para servir a la aristocracia, se dejaba traslucir en aquel reclamo clasista. ${ }^{21}$

A pesar de todo lo anterior, una vez más la contradicción dentro del universo emocional de Fanny se hace presente en su es-

20 Fanny utiliza la palabra "criada" para referirse a las trabajadoras domésticas. El sustantivo era muy utilizado en la sociedad virreinal y venía de la idea de que muchas de dichas trabajadoras habían sido huérfanas o chicas desamparadas que vivían en las casas donde trabajaban y servían; muchas de ellas habían sido criadas por las familias que las acogían en sus casas desde niñas, a cambio de obtener sus servicios domésticos. 21 Es interesante pensar, también, en cómo para Fanny, la importancia que tenía para el valor de la meritocracia seguramente provenía de su herencia protestante. Las sociedades protestantes que la vieron crecer y desarrollarse antes de su estancia en México daban un enorme valor al trabajo constante y al esfuerzo personal. 
critura cuando ésta señala que algunas criadas mexicanas sí eran muy buenas. Cuando aquello ocurría, explicaba la escocesa, éstas eran, bajo su mirada "modelo de cortesía, humildes, serviciales, de muy buen carácter y con facilidad, se aficionan a quienes sirven [...]" (Calderón de la Barca, 2000: 164).

Es interesante observar la mezcla de exigencias de eficiencia liberal con aquellas sensaciones de satisfacción al encontrar trabajadoras domésticas sumisas y obedientes que la pudieran servir adecuadamente. También lo es encontrar, entre las virtudes que la escocesa enumera para describir a las sirvientas mexicanas, la capacidad de las mismas para encariñarse con sus patrones. Los valores de la amistad, el amor, la simpatía, tan propios de la sensibilidad romántica decimonónica, se hacían presentes en dicho retrato hablado. Ahora bien, si en cierto sentido Fanny concedía ciertas cualidades a las criadas mexicanas, al mismo tiempo y, desde su conciencia de clase y su mentalidad capitalista, aquellas mujeres le parecían evidentemente inferiores y casi despreciables: "iEs tan corta la necesidad, cuando se puede vivir tranquilamente con tortillas y chile, dormir sobre un petate y vestirse de harapos!" (Calderón de la Barca, 2000: 161).

Las tensiones y contradicciones internas de Madame Calderón de la Barca se dejan ver en muchos otros momentos de su correspondencia, en especial cuando Fanny se refiere a la manera en que las mujeres mexicanas se vinculaban con los hombres en su vida cotidiana. Al respecto, Fanny explicaba, por ejemplo, cómo, por un lado, al encontrarse con las señoritas de este país atrasado y al mismo tiempo encantador -porque desde su visión europea y romántica México sí le parecía un país, cuando menos, "curioso" y "simpático"-, una de las cosas que más le sorprendían eran los pocos espacios que los jóvenes mexicanos tenían para conocerse, reunirse y ejercer la educada costumbre de la seducción entre los sexos. Así, de esta manera, Fanny señalaba: "En cuanto al flirt, no se conoce aquí ni la cosa ni el nombre" (Calderón de la Barca, 2000: 142).
Sin embargo, si bien Fanny echaba en falta las posibilidades de que los jóvenes mexicanos pudieran establecer vínculos modernos y ejercer el coqueteo civilizado, al mismo tiempo, cuando visitó el Colegio de las Vizcaínas, ésta se sintió reconfortada al mirar cómo las monjas enseñaban a las niñas "a cocinar, planchar y otras faenas domésticas, que preparan a las muchachas para que lleguen a ser buenas esposas de hombres honrados y pertenecientes a su misma condición" (Calderón de la Barca, 2000: 95).

Es decir, por más liberal, moderna e ilustrada que fuera Madame Calderón de la Barca, ésta miró con muy buenos ojos la educación femenina católica y tradicional que favorecía que las mujeres mexicanas se vincularan con sus esposos a partir de los estereotipos más conservadores de aquello que debía ser un buen matrimonio cristiano: esposas sumisas y serviciales que atendieran a sus respetables maridos.

\section{Algunas consideraciones finales}

Vida en México es expresión del cúmulo de experiencias personales que hicieron de Madame Calderón de la Barca un sujeto único, particular (Turner y Bruner, 1986: 7).22 El viaje de Fanny a México fue una experiencia vivida que solamente adquirió sentido a partir de la conciencia, y, mejor dicho, de la autoconciencia de una mujer cuya personalidad se había forjado en medio de muchas tradiciones y contextos culturales distintos y que, como se ha visto ya, eran, en muchos momentos, contradictorios. Aquella conciencia personal o yo interior femenino no se construyó en el vacío, sino en un escenario que ponía unos límites específicos a las posibilidades de su existencia. La mirada con la que Fanny se aproximó a las mexicanas y, por ende, los reflejos que a partir de ella recibió de sí misma, provenía de un drama social histórico y cultural específico:

22 Retomaré, a partir de este momento, para desarrollar mis ideas, el concepto de experiencia de Victor Turner (1986), quien señala que ésta no es otra cosa que la realidad primaria de una persona. 
el de una mujer escocesa ilustrada y liberal, inmigrante del viejo al nuevo mundo, y muy afín a los círculos intelectuales y republicanos que la acogieron, a ella y a su familia, en Boston. También, Fanny fue la mujer eurocéntrica, racista e imperialista, esposa del primer ministro español plenipotenciario de México. Ahora bien, a pesar de que, durante su estancia en México, Fanny no podría haber actuado o sentido sino a partir de esta identidad culturalmente híbrida, al mismo tiempo, es importante señalar que -como todas- aquella identidad fue compleja, dinámica y cambiante y que nunca constituyó una camisa de fuerza que la determinara o la condicionara de forma irremediable o estática. Por el contrario, el drama social en el que esta escocesa decimonónica se encontraba fue la realidad primaria sobre la cual, ella misma, como sujeto histórico activo y consciente, dio forma a las acciones y a las emociones con las que interpretó su vida y, sobre todo, con la que pudo mirar a las mujeres mexicanas que la confrontaron con lo que ella descubría de sí misma a partir de los reflejos que se generaban en el proceso de autodefinición (Turner y Bruner, 1986: 5). ${ }^{23}$

En este sentido, como para muchas otras viajeras europeas de su época, para Fanny, su estancia en México constituyó una experiencia transformadora y de autoconocimiento (Méndez Ródenas, 2014: 10). ${ }^{24}$ Como toda confrontación con la otredad, el encuentro de Madame Calderón de la Barca con sus otras mexicanas la colocó en una geografía emocional particular. Las emociones que experimentó al toparse con dichas mujeres la hicieron oscilar, de manera contante, entre "lo similar y lo distinto, lo exótico y lo doméstico, lo interno y lo externo" (Chhanda y Chattopadhyaya, 1998: 5). Así, la esposa de don Ángel Calderón de la Barca se vinculó con dichas mujeres a veces, a partir de la empatía; otras, a partir del rechazo, en ocasiones, desde la identificación -y, por lo

23 En palabras de Victor Turner, "la experiencia es personal, se refiere a un yo activo, a un sujeto que no sólo adapta una idea, sino que moldea sus acciones" (1986: $X X)$.

24 Adriana Méndez Ródenas (2014) ha señalado que dicha experiencia constituía una experiencia liminal. tanto, desde la integración momentánea a la sociedad mexicana que la acogía- y otras, desde la resistencia y la diferenciación inmediata de un mundo que despertaba en ella fuertes sentimientos de superioridad. $Y$ es que, sin duda, por momentos, Fanny pudo sentirse muy parecida a las mujeres mexicanas que, en mucho, pertenecían a una realidad cultural muy similar a la del Antiguo Régimen europeo; sin embargo, parecería que apenas se identificaba con ellas, su yo más progresista y liberal, también su yo más imperialista y eurocentrista, salía a flote para resistir y decir no: "yo soy otra cosa" (Méndez Ródenas, 2014: 11-13). ${ }^{25}$

Como se ha visto a lo largo de estas páginas, el espacio geográfico ajeno en el que Fanny experimentó aquel proceso de construcción de su yo interior femenino constituyó una zona de contacto que, sin duda, generó, también, un espacio geográfico emocional particular. Si se sigue a Marie Louise Pratt y se piensa en la zona de contacto como aquel espacio de encuentros coloniales en donde pueblos distintos se vincularon a partir de interacciones que implicaron la inequidad y el conflicto, no es difícil incluir, en dicha geografía, el conflicto y la tensión emocional. ${ }^{26}$

Más allá de los instantes en que Fanny pudo experimentar empatía, simpatía o condescendencia por sus otras mexicanas, lo cierto es que lo que se percibe en muchos momentos de su escritura es su posicionamiento de superioridad desde una identidad construida a partir de su calidad de mujer europea y poderosa. En ese sentido, bajo la mirada de Fanny, las mujeres mexicanas eran sus otras, en la medida en que dichas

25 Es probable que a esto se refiera Adriana Méndez Ródenas cuando señala que las mujeres que hicieron viajes transatlánticos en el siglo XIX vivieron fuertes tensiones internas al intentar cumplir o no con sus roles tradicionales, en medio de la experiencia de un viaje que las colocaba en sitios muy distintos. De acuerdo con la autora, dichas mujeres "buscaron identificarse con sus anfitrionas criollas, pero también buscaron mantener sus identidades europeas y de privilegio de clase" (2014: XX)

26 La definición de la zona de contacto la retomo de Mary Louise Pratt (1992), muy específicamente de su libro Ojos imperiales: escritura de viaje y transculturación. 
mujeres frívolas, incultas, atrasadas y, en el mejor de los casos, pintorescas y cariñosas, necesitaban, claramente, la intervención europea para civilizarse y progresar (Leask, 1999: 193-196). ${ }^{27}$

Como todo viaje transatlántico, el de Fanny Calderón de la Barca a México incluyó lo mismo placer que incomodidad. Basta con recordar la alegría que, al llegar, despertaron en ella los hermosos paisajes de la tierra mexicana, esto, en medio del fastidio y las incomodidades propias de una diligencia que tenía que transitar por caminos pedregosos, irregulares y accidentados de un país bárbaro y atrasado. Sin duda, si la experiencia física del viaje fue ambigua y cambiante, la experiencia emocional interior se caracterizó, sobre todas las cosas, por la ambivalencia y la fluctuación.

Sin duda, al leer el testimonio de Madame Calderón, uno no puede dejar de intentar imaginar cuáles habrían sido los efectos que, a largo plazo y ya de regreso a Europa, habría tenido la experiencia temporal de esa confrontación constante con lo que resultaba tan distinto y tan similar. ¿Cómo habría recordado Fanny su estancia en México con el paso de los años y ya de vuelta al Viejo Mundo? ¿Qué sensaciones de incomodidad o de autoafirmación habría podido experimentar aquella mujer consciente de su civilidad occidental, pero también ya transformada a partir del contacto con la otredad americana? ¿Cómo habría podido conciliar las contradicciones internas propias de la toma de conciencia de su propia identidad híbrida? En realidad, todas estas son preguntas para las cuales no hay respuestas definitivas; sin embargo, lo que sí es cierto es que frente a la posible ambivalencia y contradicción existencial experimentada por la Marquesa en tierras americanas y más tarde ya de regreso a Europa, el ejercicio de la escritura otorgó a Madame Calderón de la

27 En su artículo sobre Fanny Calderón, Nigel Leask (1999) sostiene que Madame Calderón de la Barca veía con melancolía el pasado imperial hispánico en México desde su sensibilidad romántica, pero también como una clara justificación de la necesidad del intervencionismo europeo en un país que, bajo su mirada, era, en gran medida, incivilizado.
Barca un norte y un rumbo, y, seguramente, le ofreció la posibilidad de construir sentimientos de firmeza y estabilidad en muchos momentos de su vida. Y es que como se ha mencionado ya, Vida en México fue escrita, en realidad, no como un libro, sino como expresión de la experiencia de muchos sentimientos de inquietud y movilización interna generados a partir del encuentro con lo distinto. Es decir, en las cartas a su madre y a sus hermanas -esto es, lo que ella concebía como sus iguales-, Fanny buscó dar voz a un diálogo interno que sin duda la llenaba de tensiones y contradicciones no siempre fáciles de manejar. Así, el escribir dio a Fanny la posibilidad de nombrar lo propio y lo ajeno con mayor tranquilidad. La escritura, entonces, habría sido la expresión misma de un universo interno, incierto y cambiante, originado a partir del desplazamiento físico y a su vez, emocional, en el que Fanny experimentó el complejo encuentro con la otredad; un encuentro, que, en realidad, significó el encuentro constante con su propia conciencia planetaria europea, es decir, el encuentro transatlántico consigo misma (Chedgzoy, 2012: 3). ${ }^{28}$

\section{Fuentes consultadas}

Calderón de la Barca, Fanny (2000), La vida en México durante una residencia de dos años en ese país, Ciudad de México, Editorial Porrúa.

Chedgzoy, Kate (2012), Women's Writing in the British Atlantic World: Memory, Place and History 1500-1700, Cambridge, Cambridge University Press.

Chhanda, Gupta y Chattopadhyaya, D.P. (eds.) (1998), Cultural Otherness and Beyond, Leiden/Boston/Koln, Brill.

28 Es Kate Chedgzoy quien explica cómo para las mujeres inglesas que realizaron viajes transatlánticos en el siglo XIX, escribir se convirtió en un ejercicio para "nombrar experiencias de pertenencia y de desplazamiento en un mundo cambiante". Por su parte, Mary Louise Pratt (1992) utiliza el concepto de "conciencia planetaria europea" para describir la construcción de las miradas imperiales presentes en los relatos de viaje del siglo XIX. 
Crouzet, Denis y Zemon Davies, Natalie (2006), Pasión por la historia. Entrevista con Natalie Zemon Davies, Valencia, Publicacions de la Universitat de València.

Ferrús Antón, Beatriz (2011), Mujer y literatura de viajes en el siglo XIX: entre España y las Américas, Valencia, Publicacions de la Universitat de València.

Fisher Alan H. (ed.) (2018), Frances Calderón de la Barca née Frances Erskine Inglis. A biography of the autor of Life in Mexico and The Attaché in Madrid, Harvard, Harvard University.

Gerassi, Nina (2009), "Conflictos imperiales: la mirada de Frances Calderón de la Barca", Revista Iberoamericana, LXXV, (228), Pittsburg, University of Pittsburg, <https://bit.ly/37CAjPI>, 12 de agosto de 2021.

Gilroy, Amanda (ed.) (2000), Romantic Geographies: Discourses of Travel 17751844, Manchester, Manchester University Press.

Hagglund, Betty (2010), Tourists and Travellers: Women's Non-fictional Writing about Scottland 1770-1830, Londres, Channel View Publications.

Hunt, Eileen (2014), “Theorizing Women's Political Agency from the Margins of Hannah Mather Crocker's Reminiscences and Traditions of Boston", Chapel Hill, The University of North Carolina Press.

Leask, Nigel (1999), "The Ghost of Chapultepec: Fanny Calderón de la Barca, William Prescott on XIX Century Mexican Travel Accounts", en Ja Elsner y Joan-Pau Rubiés (eds.), Voyages and Visions: Towards a Cultural History of Travel, Londres, Reaktion Books.

Mellor, Anne K. (1993), Romanticism and Gender, Nueva York, Routledge.

Méndez Ródenas, Adriana (2014), Transatlantic Travels in Nienteenth Century Latin America: European World Pilgrims, Maryland, Bucknell University Press.
Norquay, Glenda (2012), Edimburgh Companion to Scottish Women's Writing. Edimburgo, The Edimburgh University Press.

Pratt, Mary Louise (1992), Imperial Eyes: Travel Writing and Transculturation, Nueva York, Routledge.

Ramírez Rodríguez, Rodolfo (2010), "Fanny Calderón de la Barca y su percepción romántica de México", Históricas, 88, Ciudad de México, UNAM-Instituto de Investigaciones Históricas, <https://bit. ly/3jRwPOt>, 12 de agosto de 2021.

Simonton, Deborah y Barclay, Katie (eds.) (2016), Women in XVIII Century. Scotland: Intimate, Intelectual and Public lives, Nueva York, Routledge.

Standish, Peter (2010), "La mujer de Calderón", Actas XLV de la Asociación Europea de Profesores de Español, Madrid, Centro Virtual Cervantes, <https://bit. ly/3jStFdo>, 12 de agosto de 2021.

Teixidor, Felipe (2000), "Prólogo", en Fanny Calderón de la Barca, La vida en México durante una residencia de dos años en ese país, Ciudad de México, Editorial Porrúa.

Turner, Victor y Bruner, Edward (eds.) (1986), The Anthropology of Experience, Chicago, The University of Illinois Press.

Wolfson, Susan (2015), "Romanticism and Gender and Melancholy", Studies in Romanticism, 53 (3), Boston, Boston University, pp. 435-456.

Recibido: 1 de septiembre de 2021. Aceptado: 5 de octubre de 2021 Publicado: 6 de enero de 2022. 


\section{Estela Roselló Soberón}

Es doctora en Historia por El Colegio de México. Actualmente es investigadora de tiempo completo en el Instituto de Investigaciones Históricas de la UNAM y profesora en la Facultad de Filosofía y Letras de la misma institución. Es miembro del Sistema Nacional de Investigadores, nivel II. Sus líneas de investigación están relacionadas con temas vinculados con la historia cultural, la historia de las mujeres, las emociones, el cuerpo y la otredad. Entre sus más recientes publicaciones destacan, como autora: "Historias verdades -o no- sobre la experiencia emocional y corporal de la otredad. Los contactos entre indios y españoles, previos a la guerra en México Tenochtitlán", Frontería. Revista do Programa de Pós-Graduacao em Literatura Comparada, 1 (1), Foz do Iguaçu, Universidade Federal da Integração Latino-Americana (UNILA), pp. 182-206 (2020); Melancolía y depresión en el tiempo: cuerpo, mente y sociedad en los orígenes de una enfermedad emocional, Ciudad de México, Conferencia Interamericana de Seguridad Social para el Bienestar (2020). 


\section{IA SORPRERA.}

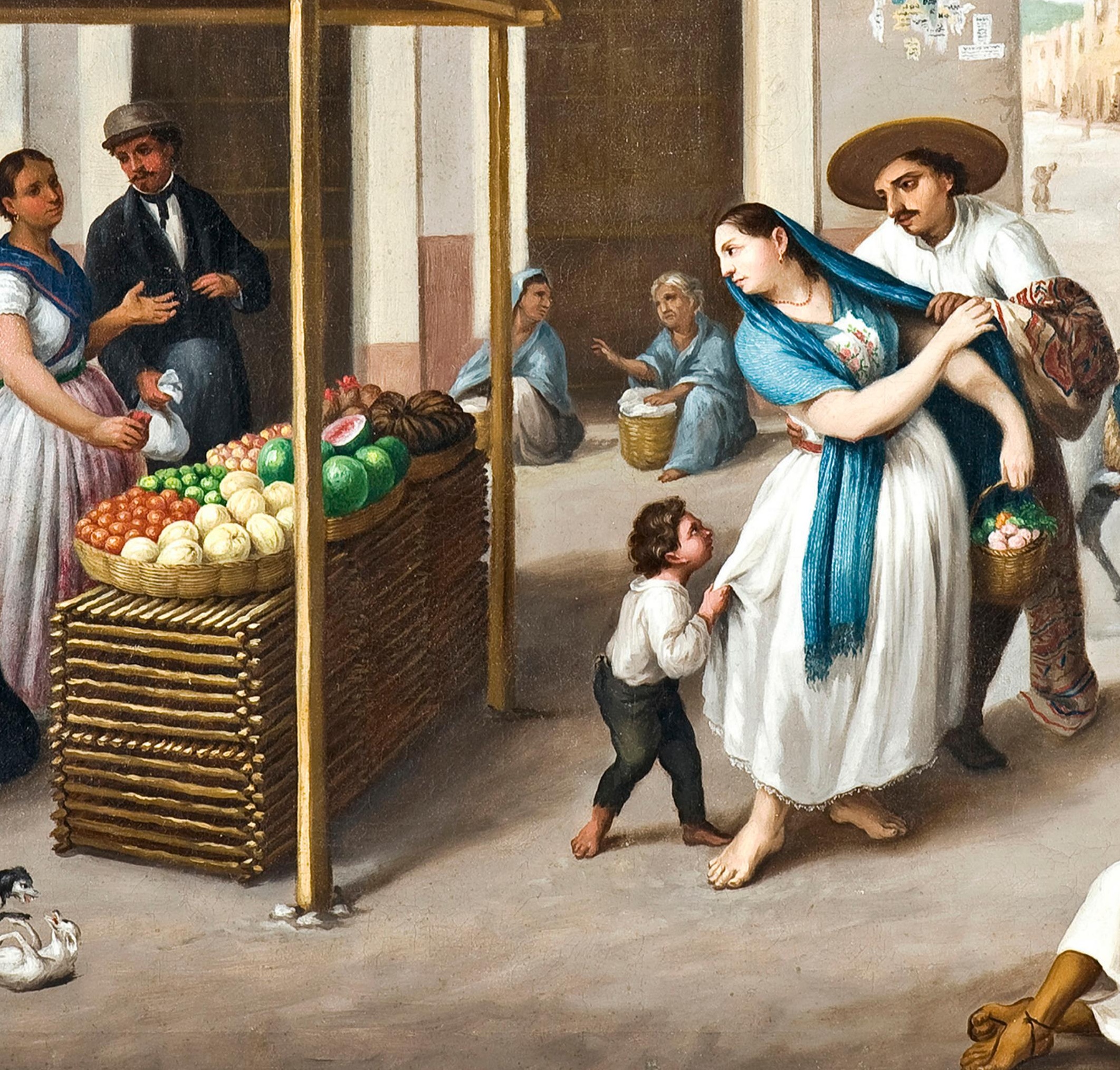

